\title{
Sexual Identity, Preference and Prevalence of Forced Sexual Intercourse among Young People in an Urban Community in Ovia North East Local Government Area, Edo State, Nigeria
}

\author{
C. Okafor Kingsley ${ }^{1}$, C. Azuike Emmanuel ${ }^{2 *}$, Y. Adam Vincent ${ }^{3}$ \\ ${ }^{1}$ Department of Public Health, Federal Medical Centre, Keffi, Nigeria \\ ${ }^{2}$ Department of Community Medicine, Chukwuemeka Odumegwu Ojukwu University Teaching Hospital, \\ Awka, Nigeria \\ ${ }^{3}$ Department of Community Medicine, University of Benin Teaching Hospital, Benin City, Nigeria \\ Email: *emmanazuike@yahoo.com
}

How to cite this paper: Kingsley, C.O., Emmanuel, C.A. and Vincent, Y.A. (2018) Sexual Identity, Preference and Prevalence of Forced Sexual Intercourse among Young People in an Urban Community in Ovia North East Local Government Area, Edo State, Nigeria. Advances in Sexual Medicine, 8, 25-38.

https://doi.org/10.4236/asm.2018.83003

Received: May 31, 2018

Accepted: July 21, 2018

Published: July 24, 2018

Copyright $\odot 2018$ by authors and Scientific Research Publishing Inc. This work is licensed under the Creative Commons Attribution International License (CC BY 4.0).

http://creativecommons.org/licenses/by/4.0/ (c) (i) Open Access

\begin{abstract}
Background: Young people are at risk of being victims or perpetrators ofcoerced or forced sexual sex. In predominantly low- and middle-income countries, this contributes significantly to their risk for HIV infection, unwanted pregnancy, and sexually transmitted diseases. Current trends show that young people sexual identity and preferences affect their sexual and reproductive health. Objective: This study aims to determine prevalence of coerced or forced sexual intercourse, sexual identity and sexual preferences of young people in Oluku Community, Ovia North East, Local Government, Edo State, South Nigeria. Methods: A descriptive cross-sectional study conducted in June, 2013 using multi-stage sampling method. Results: A total of 400 young people participated in this study. The mean age was $17.8 \pm 3.9$ years. A higher proportion of respondents were of the Bini ethnic group 145 (36.3\%). Most respondents were Christians 346 (86.5\%) while 33 (8.2\%) were Moslems. Majority of the respondents had secondary education 271 (67.8\%), most were single $363(90.8 \%)$ and were from families with a monogamous setting 289 $(72.3 \%)$. The prevalence of forced sex was $12.9 \%$, similarly, condom use during forced sex was $27.8 \%$. More females (15.3\%) than males (9.6\%) had experienced forced sex; forced sex was common among young people from older age group, monogamous homes, and those living in a flat or self contained. Majority (95.3\%) of adolescent's sexual preference was vaginal, only a few preferred oral (3.3\%) and anal sex (1.5\%). Religion was associated with sexual preference and identity. The sexual identity of most (98.0\%) young person's
\end{abstract}


was heterosexual (or different sex), while $0.5 \%$ were homosexual (or same sex) and $1.5 \%$ bisexual (or both). Conclusion and Recommendations: Legislation against forced and coerced sex, rape and other forms of sexual violence should be formulated and implemented.

\section{Keywords}

Sexual Identity, Sexual Preferences, Homosexuals, Forced/Coerced Sex, Young People

\section{Introduction}

Adolescents and young people constitute about $20 \%$ of the world's population and their reproductive health needs remain poorly understood and inadequately served in many parts of the world [1]. Young people are typically poorly informed about how to protect their sexual and reproductive health [1] [2]. This lack of adequate information and guidance about sex and sexuality make young people vulnerable to diseases and physical, emotional and economic exploitation. They unknowingly engage in sexual risk behaviour's that might expose them to diseases and unplanned pregnancies [1] [2] [3].

Coerced or forced sexual sex contributes significantly to a woman's risk for Human Immunodeficiency Virus (HIV) infection and Sexually Transmitted Infections (STI). In predominantly low- and middle-income countries, coerced/ forced sex was associated with HIV/STIs, multiple and high-risk sex partners, and no condom use [4]. Young people and adolescents are usually victims of forced sex. Forced sexual intercourse is violence against the victim that occurs in a situation where there is a power difference. The perpetrator has power over the victim, making it difficult for the victim to negotiate the use of a condom. Younger women and girls are at particularly high risk as they are easily overpowered by the perpetrator and have a high chance of becoming infected with HIV, because of vaginal injuries and bruises are sustained during forced sex, rape or sexual abuse [5]. In addition, sexual coercion is a widespread phenomenon, and in some countries between $20 \%$ and $48 \%$ of young women aged $10-25$ years have been forced to have sex [4] [6] [7]. The prevalence of forced or coerced sex among adolescent girls aged 15 years and younger ranging from $11 \%$ to $45 \%$, globally [6]. Approximately 150 million girls and 73 million boys under 18 experienced forced sexual intercourse or other forms of sexual violence during 2002 [8]. This can lead to reproductive health problems like unwanted pregnancy, abortion and its complications, sexually transmitted infections (STIs) including the acquired immunodeficiency syndrome (AIDS) [9] [10].

Young people develop their capabilities by trying out new behaviours, skills, opportunities, hobbies and relationships, each of which has health implications. Sexual identities or orientation like heterosexual relationships are considered normal, but some young persons may be exploring sexual relationships with 
partners of the same or both sexes, sexually attracted to persons of same sex in a homosexual or gay/lesbian relationship [11]. This group of young people is referred to as "sexual minority youth". They are usual social and personal challenges which may be compounded by rejection by their peers, social isolation, verbal abuse, physical violence, and poor access to confidential health care due to their sexual identity. Sexual preference may be a means of disease transmission or they themselves may be disproportionately prone to depression, suicidal ideation, substance abuse, and adverse sexual health outcomes (e.g., unintended pregnancy and sexually transmitted infections [STIs]) [11].

Youths with different sexual identities and preferences like gays, lesbians and bisexual make up a relatively small proportion of sexually active in-school youth (5\% - 6\%) [12] [13]. High rates of risky sexual behaviours among sexual minority youth have been documented amongst them. Thus controlling these risks is important to public health [12] [14].

The objectives of this study were to determine the prevalence of coerced or forced sexual intercourse among young people, their sexual identity sexual preferences, and reasons for their preference and identity.

\section{Methodology}

A descriptive cross-sectional study was carried out between January to June, 2013 among 400 selected young people in Oluku community.

Respondents were selected using multi stage sampling method involving the following stages:

Stage one: The Lagos-Benin express road divides the community into a two halves, one on the right (as community 1) and the other on the left (as community 2). A simple random sampling technique using a table of random numbers was used to select one of the two communities. The left community (community 2) was selected.

Stage two: The number of houses and households in the selected community was determined by counting and numbering. There were 172 houses and 526 households on the left side of the community (Data from an initial enumeration done by researcher). From this, 400 households were selected using a simple random sampling (using a table of random numbers). In households with more than one adolescent, an adolescent was selected by balloting.

Young People refers to a period of life and the health development between 10 - 24 years of age. Sexual preferences is used in this context to describe the method of sexual activity like vaginal sex, anal sex, oral sex based on the choice of the individual while Sexual identity refers to sexual affiliation to either same sex (gayism or lesbianism),or different sexes.

Data collection tools were pre-tested among young people in Ogbona community in Etsako Central Local Government Area, Edo State, which is about 300 $\mathrm{km}$ away from Oluku community. The instrument was tested for correctness and appropriate understanding by the respondents. The ability of research assis- 
tants' to fill the questionnaires appropriately was also assessed. All ambiguous questions were deleted to reduce the possibility of information bias. Data was collected using quantitative method adapted from the 2007 National HIV/AIDS and Reproductive Health Survey (NARHS) plus [15]. The variables sought were in line with the objectives of the study. Survey tool had a Cronbach alpha of 0.8 which is within acceptable limits.

A structured, interviewer administered questionnaires covered socio-demographic data, sexual debut, ever had forced sexual intercourse, number of times they were forced to have sexual intercourse, use of condom during forced sex, who perpetuated the forced sex, sexual preferences (vaginal, anal, oral), reason for preference, sexual identity (same sex, different sex, both). Questionnaire contained twenty two questions related to the objectives of the study.

Collected quantitative data was entered and analyzed using Statistical Package for Scientific Solution (SPSS) version 19. Descriptive and inferential analysis was carried out in line with the objectives of the study.

Quantitative variables that are normal in distribution such as age and weight were expressed as means \pm standard deviation. Qualitative data like gender, educational status, and marital status were presented as diagrams and percentages. Statistical test of association, were carried out using a 95 percent confidence interval.

Ethical approval was obtained from the ethical committee of the University of Benin Teaching Hospital. Permission was obtained from the community leader and youth leaders, while parents gave assent for questionnaires to be administered. Individual informed consent was attached to each questionnaire and the respondent gave his or her consent before the questionnaires were filled.

\section{Results}

\subsection{Socio-Demographic Characteristics}

The age groups 15 - 19 years and 20 - 24 years constituted the greatest percentage with $38.0 \%$ and $36.0 \%$ respectively. The mean age was $17.8 \pm 3.9$ years. There were more females 211 (52.8\%) than males 189 (47.3). A higher proportion of respondents were of the Bini ethnic group 145 (36.3), others were Igbo 85 (21.3\%), Yoruba 74 (18.5\%), Esan 26 (6.5\%). Most respondents were Christians $346(86.5 \%)$ while $33(8.2 \%)$ were Moslems. Majority of the respondents had secondary education $271(67.8 \%)$, while $6(1.5 \%)$ did not attend formal education. Most of the respondents were single 363 (90.8\%) and were from families with a monogamous setting 289 (72.3\%). Seventy percent of young person's came from families with more than four persons in the family. A higher proportion of young person's live in flats or self contained 245 (61.3\%), while 155 $(38.8 \%)$ live in a shared apartment or passage house. A majority of young person's attended or was attending day schools 316 (79.0\%).

Over two thirds of respondents resided with their parents, while a fourth of them resided with their guardians. About half 203 (50.7\%) of the respondents 
had fathers who had tertiary level of education 52 (13\%) had fathers with no formal education, while about a third had fathers with secondary education. Also, slightly more than a third of respondents 139 (34.8\%) had mothers who had secondary and tertiary level of education, while 71 (17.8\%) had no formal education.

\subsection{Prevalence of Forced Sex and Predictive Factors among Respondents}

The prevalence of forced sex among respondents was $12.9 \%$, and condom use during forced sex was reported to be $27.8 \%$. Multiple forced sex occurred in 21 (84.0\%) of respondents (Table 1 ).

Prevalence of forced sex decreased as age of respondents increased. This association was not statistically significant $(\mathrm{p}=0.572)$. Females $17(15.3 \%)$ experienced more forced sexual intercourse than males 8 (9.6\%). This association was not statistically significant $(\mathrm{p}=0.171)$. A higher proportion of Christians 145 (89.0\%) had not experienced forced sexual intercourse when compared with respondents of other religion. This was not statistically significant. ( $p=0.286$ ). Respondents in a monogamous 21 (16.4\%) family setting experienced more forced sex than those in polygamous $3(5.3 \%)$ or separated families $1(11.1 \%)$ This association is not statistically significant $(\mathrm{p}=0.081)$. Respondents living in passage house $9(13.2 \%)$ had a higher prevalence of forced sex, than those living in flats or self contained $16(12.7 \%)$. This association is not statistically significant $(\mathrm{p}=0.540)$. An almost equal proportion of respondents who attended day school $20(13.4 \%)$ and those who attended boarding school $5(11.1 \%)$ had experienced forced sexual intercourse. This was not statistically significant $(\mathrm{p}=0.708)$ (Table 2).

\subsection{Sexual Preferences and Sexual Identity and Reasons for Preference and Identity}

Majority (95.3\%) of respondents prefer vaginal sexual intercourse, while 6 (1.5\%) and 13 (3.3\%) prefer anal and oral sex respectively. A higher proportion

Table 1. Prevalence of forced sex among respondents.

\begin{tabular}{ccc}
\hline Variables & Frequency & Percent \\
Forced Sex $(\mathbf{n}=194)$ & 25 & 12.9 \\
Yes & 169 & 87.1 \\
No & & 16.0 \\
Number of times respondents had forced sex $(\mathbf{n}=25)$ & 4 & 44.0 \\
Once & 11 & 22.5 \\
$\mathbf{2}$ times & & 6 \\
$\mathbf{3}$ - $\mathbf{2}$ times & 6 & 17.5 \\
\hline
\end{tabular}


Table 2. Predictor variables of Forced sex of respondents.

\begin{tabular}{|c|c|c|c|c|}
\hline \multirow{2}{*}{ Predictor variable } & \multicolumn{2}{|c|}{ Forced or coerced sex } & \multirow{2}{*}{ Fisher exact } & \multirow{2}{*}{$\mathrm{p}$ value } \\
\hline & Yes (\%) & No (\%) & & \\
\hline \multicolumn{5}{|l|}{ Age (years) } \\
\hline $10-14$ & $1(16.7)$ & $5(83.3)$ & & \\
\hline $15-19$ & $12(15.8)$ & $64(84.2)$ & 1.756 & 0.572 \\
\hline $20-24$ & $12(10.7)$ & $100(89.3)$ & & \\
\hline \multicolumn{5}{|l|}{ Sex } \\
\hline Male & $8(9.6)$ & $75(90.4)$ & 3.873 & 0.171 \\
\hline Female & $17(15.3)$ & $94(84.7)$ & & \\
\hline \multicolumn{5}{|l|}{ Religion } \\
\hline Christianity & $18(11.0)$ & $145(89.0)$ & 3.783 & 0.286 \\
\hline Islam & $5(26.3)$ & $14(73.7)$ & & \\
\hline Traditional & $1(14.3)$ & $6(85.7)$ & & \\
\hline None & $1(20.0)$ & $4(80.0)$ & & \\
\hline \multicolumn{5}{|l|}{ Family structure } \\
\hline Monogamous & $21(16.4)$ & $107(83.6)$ & 4.389 & 0.081 \\
\hline Polygamous & $3(5.3)$ & $54(94.7)$ & & \\
\hline Separated & $1(11.1)$ & $8(88.9)$ & & \\
\hline \multicolumn{5}{|l|}{ Residence of respondents } \\
\hline Shared/Passage House & $9(13.2)$ & $59(86.8)$ & 4.872 & 0.540 \\
\hline Flat/self contained & $16(12.7)$ & $110(87.3)$ & & \\
\hline \multicolumn{5}{|l|}{ Type of School } \\
\hline Day School & $20(13.4)$ & $129(86.6)$ & 8.907 & 0.708 \\
\hline Boarding & $5(11.1)$ & $40(88.9)$ & & \\
\hline Total & $25(12.9)$ & $169(87.1)$ & & \\
\hline
\end{tabular}

of respondents reported their preference was "normal" 221 (55.3\%), 10 (2.5\%) reported their preference to be the "better", 157 (39.2\%) gave reason for their preference as "morally right", while $4(1.0 \%)$ reason their sexual preference as "safer" (Table 3).

Two (0.5\%) of respondents were homosexuals, majority (98.0\%) of respondents reported that heterosexual intercourse was their sexual identity (orientation), while 6 (1.5\%) were bisexual. A higher proportion of respondents reported their sexual identity was "normal" $226(56.5 \%), 3$ (0.8\%) reported their sexual identity to be the "better, $168(42.0 \%)$ gave reason for their sexual identity as morally right, while $1(0.2 \%)$ reason their sexual identity as safer (Table 3 ).

Majority of the adolescent who were Christians 343 (99.1\%) and Muslims 93 (93.9\%) had different sex as their sexual identity. The association between religion and sexual identity was statistically significant $(p=0.001)$. Respondent with 
Table 3. Sexual preferences and identity and reasons for preference and identity.

\begin{tabular}{|c|c|c|}
\hline Variables & Frequency & Percent \\
\hline \multicolumn{3}{|c|}{ Sexual Preference } \\
\hline Vaginal & 381 & 95.3 \\
\hline Anal & 6 & 1.5 \\
\hline Oral & 13 & 3.3 \\
\hline \multicolumn{3}{|c|}{ Reasons for preference } \\
\hline Normal & 221 & 55.3 \\
\hline Better & 10 & 2.5 \\
\hline Pleasurable & 8 & 2.0 \\
\hline Morally right & 157 & 39.2 \\
\hline Safer & 4 & 1.0 \\
\hline \multicolumn{3}{|l|}{ Sexual Identity } \\
\hline Same Sex & 2 & 0.5 \\
\hline Different Sex & 392 & 98.0 \\
\hline Both & 6 & 1.5 \\
\hline \multicolumn{3}{|c|}{ Reasons for preference } \\
\hline Normal & 226 & 56.5 \\
\hline Better & 3 & 0.8 \\
\hline Pleasurable & 2 & 0.5 \\
\hline Morally right & 168 & 42.0 \\
\hline Safer & 1 & 0.2 \\
\hline Total & 400 & 100.0 \\
\hline
\end{tabular}

same sex identity were $2(0.5 \%), 6(1.5 \%)$ were bisexual. Respondents in with tertiary level of education had more same sex or bisexual identity (6.9\%) than those with primary or secondary level of education. The association between education and sexual identity was statistically significant $(\mathrm{p}=0.042)$ (Table 4).

Majority of the respondents who were Christians 342 (98.8\%) and Muslims 26 (78.8\%) had vaginal sex as their sexual preference. The association between religion and sexual preference was statistically significant $(\mathrm{p}=0.003)$. More males 3 (1.6\%) than females $3(1.4 \%)$ prefer anal sex. While more females 7 (3.3\%), than males 6 (3.2) prefer oral sex. This relationship was not statistically significant ( $p$ $=0.986)$. Residents of passage house prefer anal $5(3.2 \%)$ and oral sex $6(3.9 \%)$ to those living in flats or self contained. This is statistically significant.

Preference for anal sex and oral sex increases as age increases, while all 100 (100.0\%) respondents less than 14 years, 150 (97.4\%) of 15 - 19 year olds, 131 $(89.7 \%)$ of 20 - 24 year olds preferred vaginal sex. This association was statistically significant $(\mathrm{p}=0.002)$. All respondents with no formal education preferred only vaginal $4(100.0 \%)$ sex, while $64(91.4 \%)$ of those with primary school education preferred vaginal sex. Respondents with tertiary education preferred oral 
Table 4. Multivariate logistic regression for predictors of homosexuality/bisexuality.

\begin{tabular}{|c|c|c|c|c|c|}
\hline \multirow{2}{*}{ Factors } & \multirow{2}{*}{ B coefficient } & \multirow{2}{*}{$p$ value } & \multirow{2}{*}{ OR } & \multicolumn{2}{|c|}{$95 \%$ confidence interval } \\
\hline & & & & Lower limit & Higher limit \\
\hline \multicolumn{6}{|l|}{ Level of education } \\
\hline Primary or none & 0.527 & 0.650 & 1.694 & 0.174 & 16.469 \\
\hline \multicolumn{6}{|c|}{ Secondary and tertiary* } \\
\hline \multicolumn{6}{|l|}{ Religion } \\
\hline Christianity & -1.045 & 0.372 & 0.352 & 0.035 & 3.489 \\
\hline Islam & -18.862 & 0.998 & 0.000 & 0.000 & \\
\hline Constant & -2.470 & 0.029 & 0.085 & & \\
\hline
\end{tabular}

${ }^{*}$ Reference value. Significant Reference category, $\mathrm{R}^{2}$ (coefficient of determination) $=0.1 \%$ to $0.5 \%$.

$2(3.8 \%)$ and anal sex $2(3.8 \%)$, while of those with secondary education $2(0.7 \%)$ and $7(2.6 \%)$ preferred anal and oral sex respectively. This was not statistically significant $(\mathrm{p}=0.419)$.

More residents of passage house preferred anal sex 5 (3.2\%) and oral sex 6 (3.9\%) when compared with respondents who reside in flats or self contained. This relationship was statistically significant $(\mathrm{p}=0.046)$. A higher proportion of respondents who are Edo 4 (2.1\%) than those who were non Edo 2 (1.0\%) had anal sex as their sexual preference, while a higher proportion of non Edo 9 (4.3\%) than Edos 4 (2.1\%) prefer oral sex. The association between ethnic group and sexual preference was not statistically significant $(\mathrm{p}=0.308)$ (Table 4).

\section{Discussion}

Youths (15 - 24 years) constituted the greatest percentage of respondents with a mean age was $17.8 \pm 3.9$ years. This is similar to studies done in Ibadan [16], Calabar [17], Anambra [18] and National HIV/AIDS and Reproductive Health Survey, 2008 [15]. This is because for the first time in global population history, the number of people in the world aged 12 - 24 is the largest ever, currently, there are 1.3 billion people in this age group [2]. Sex distribution showed there were slightly more females than males. This is in similar to studies done in Ibadan [16], Owerri [19], the Edo State Strategic Health Development Plan [20] the 2008 NDHS [21] and the UNFPA Nigerian adolescent population survey [3] [22] where males and females also had almost equal proportion, with $50.1 \%$ males and $49.9 \%$ females. A higher proportion of respondents were of the Bini ethnic group, others were Igbo, Yoruba, Esan. This is because majority of the inhabitants of Edo State are of Bini ethnic group [23]. Most respondents were Christians. A possible explanation is the fact that Christianity is the most predominant religion in southern part of Nigeria and Edo State [23]. Over two thirds of the young people had secondary education as their minimum qualification, $17.8 \%$ had primary education, $1.5 \%$ had no formal education; this is in contrast with the UNFPA adolescent and young people's survey where $35.3 \%$ secondary 
school education, $34.1 \%$ had primary education while nearly one in three (27.2\%) adolescents did not have any formal education. The proportion of adolescent with post secondary education is only about 3.1\% [22]. A possible explanation for this disparity is the fact that most secondary schools students are young people, also with the commencement of the Universal Basic Education (UBE) program that grants free education to students from primary school to Junior Secondary School, enrollment into secondary school may have increased. Thus, secondary schools can be used to means enlighten young person's on sexual and reproductive health matters. Most of the respondents were single and were from families with a monogamous setting. This finding is similar to findings from study done in Ibadan [16], and studies done by UNFPA where about $16 \%$ of adolescents were married [22]. Seventy percent of young person's in Oluku came from families with more than four persons in the family. This is consistent with findings from the 2008 National Demographic and Health Survey, which indicated that the average household size was 4.4 persons [21]. This may due to the fact that the recommended number of children per family in Nigeria is four. About half of respondents live in flats or self contained, while a over a third live in a shared apartment. Flats and self contained apartment creates a private environment for adolescents to indulge and practice risky sexual behaviour. Similarly, a majority of them attended or were attending day schools. This affords young people an opportunity to have access to parental supervision at home. Over two thirds of respondents resided with their parents, while a forth of them resided with their guardians. About half of the respondents had fathers who had tertiary level of education, $13 \%$ had fathers with no formal education, while about a third had fathers with secondary education. Also, a third of respondents had mothers who had secondary and tertiary level of education, while $17.8 \%$ had no formal education. This is similar to study done in Anambra [18]. Thus, most parents and guardians were educated enough to be able to discuss and explain sexual issues with their children and wards.

The prevalence of forced sex among respondents was 12.9\%. Much higher prevalence were recorded in Limpopo [5], South Africa (16.9\%), China [24] (23.5\%) and Leeds, United Kingdom [12] (23.0\%). Local studies that measured forced sex where not available. These countries with higher prevalence of forced sex have also reported high incidence of date rape, gang rape and other forms of sexual violence [5] [12] [24]. Also, they have a stable and reliable reporting system for such criminal act, unlike in our locality where forced sex is under reported due to societal stigma, fear and poor law enforcement [25].

Over $27 \%$ of respondents used condom during forced sex. In South Africa [5], a higher proportion (44.7\%) used condoms during forced sex. Most respondents had experienced forced sex once or twice, while $17.5 \%$ had experienced it five or more times. This is may be due to the fact that forced sex may not be have been planned by the respondent. This situation can lead to unintended pregnancies and spread of HIV/AIDS. In addition, gang rape or date rape which is common in South Africa where forced sexual initiation is reported by almost a third of 
adolescent girls, which is often pre-planned, thus most assailants use a condom during forced sexual intercourse [26]. In addition coerced sex is a common problem in schools, workplaces and amongst peers in South Africa. The prevalence of forced sex increased as the age of respondents increased. This association was not statistically significant $(\mathrm{p}=0.572)$. More females $(7.6 \%)$ experienced more forced sexual intercourse than males (4.8\%). This association was not statistically significant $(\mathrm{p}=0.171)$. This finding was similar to that found in study done in Limpopo [5]. This is attributable to the fact that females are physically weaker than the males, thus may be helpless in forced sex situations. A higher proportion of Christians had not experienced forced sexual intercourse when compared with respondents of other religion. This was statistically significant. $(p=0.286)$. Young person's from monogamous families experienced more forced sex than those in polygamous or separated families. This association is not statistically significant $(\mathrm{p}=0.081)$. Young person's living in Flat or self contained had a higher prevalence of forced sex, than those living in a passage house and shared apartment. This association is not statistically significant $(\mathrm{p}=0.800)$. Flats or a self contained house creates a private environment that can lead to forced sex, while shared or passage houses tend to be more public, thus forced sexual intercourse may not occur very often. An almost equal proportion of respondents who attended day school and boarding school had experienced forced sexual intercourse. This was not statistically significant $(p=0.708)$. Forced sex in this study did not show peculiarity to type of school due to the fact that the acts are usually independent of the type of school attended.

Majority of respondents prefer vaginal sexual intercourse, while a few mentioned anal sex (1.5\%) and oral sex (3.3\%) as their sexual preference. This finding is similar to a study done in Ibadan [16] where $98.5 \%$ preferred vaginal sex. However, a higher proportion also preferred anal sex (15.2\%) and Oral sex (47.2\%) when compared with this study. This difference may be due to the multiple responses used in the Ibadan study. A higher proportion of respondents reported their preference was "normal" (55.3\%), and morally right (39.2\%), while a few $(2.5 \%)$ reported their preference to be the "better", and safer (1.0\%). Majority of the respondents who were Christians 342 (98.8\%) and Muslims 26 (78.8\%) mentioned vaginal sex as their sexual preference. The association between religion and sexual preference was statistically significant. This is because vaginal sex is the sexual preference approved as normal in the teachings of both religions. Other sexual preferences are regarded as sinful and should attract the wrath of both man and God. More males than females prefer anal sex. This finding is attributable to the fact that male homosexuals have anal sex, while females still have both orifices for sexual pleasure, with majority preferring the vagina. In contrast, more females, than males prefer oral sex. These relationships were not statistically significant. More residents of passage house prefer anal and oral sex than those living in flats or self contained. This is statistically significant. Preference for anal sex and oral sex increases as age increases, while all respondents less than 14 years, $97.4 \%$ of 15 - 19 year olds and $89.7 \%$ of 20 - 24 year olds 
preferred vaginal sex. This association was statistically significant $(\mathrm{p}=0.002)$. This finding may be due to a higher exposure to internet and pornography as age increases. All respondents with no formal education preferred only vaginal sex, while $91.4 \%$ of those with primary school education preferred vaginal sex. More respondents with tertiary education preferred oral and anal sex than those with secondary education and those without education. This was not statistically significant. This shows that as education and exposure to western civilization and education increases, practice of anal and oral sex increases. This is in line with current trends in global sexual perception where oral and anal sexes are considered normal sexual preferences. More residents of passage house preferred anal sex and oral sex when compared with respondents who reside in flats or self contained. This relationship was statistically significant $(p=0.046)$. A higher proportion of respondents who are Edo than those who were non Edo preferred anal sex, while a higher proportion of non Edo than Edos preferred oral sex. The association between ethnic group and sexual preference was not statistically significant.

Majority of respondents identified different sex sexual intercourse (heterosexual) as their sexual identity, while $1.5 \%$ and $0.5 \%$ identified both (bisexual) and same sex (homosexual) as their sexual identity respectively. This is similar to a study done in New York [11] which showed 90.9\% identified as heterosexual, $5.4 \%$ identified as bisexual, $1.1 \%$ as gay/lesbian (homosexual) and $2.6 \%$ unsure of their sexual identity. A higher proportion of respondents reported their sexual identity was "normal" and "morally right". The reported low prevalence of homosexual identity may be as a result of societal and religious disapproval of same sex relationships. Although, this disapproval is gradually waning as gay/lesbian groups have launched protests for legalization and acceptance of their sexual identity. Majority of the adolescent who were Christians 343 (99.1\%) and Muslims 93 (93.9\%) had different sex (heterosexual) as their sexual identity. The association between religion and sexual identity was statistically significant. This is possible as religion regards same sex relationship as sinful, thus perpetrators are not accepted into the fold. Respondents in with tertiary level of education had more same sex or bisexual identity (6.9\%) than those with primary or secondary level of education. The association between education and sexual identity was statistically significant. This may be attributable to exposure of young persons with tertiary level of education have access to sexual, disposition and identities of western worlds via internet, videos, movies and literature. Also, this group may be more willing to disclose their identity than the much younger respondents who are in primary and secondary schools.

\section{Conclusions}

The prevalence of forced sex was $12.9 \%$; similarly, condom use during forced sex was $27.8 \%$. More females than males had experienced forced sex, while forced sex was common among young people from older age group, monogamous homes, and those living in a flat or self contained. 
Majority of adolescent's sexual preference was vaginal, only a few preferred oral and anal sex. Most felt their choice was normal and morally right. Religion was associated with sexual preference and identity, as most Christians and Muslims preferred vaginal sex and identified with heterosexual sex. The sexual identity of most young people was heterosexual (or different sex), while a few were homosexual (or same sex) and bisexual (or both). Education was associated with sexual identity as young people in with tertiary level of education had more same sex or bisexual identity than those with primary or secondary level of education.

The study had limitations as young people interviewed were uncomfortable answering questions on sexual issues because of its sensitive nature, thus may have given responses that may not be a true representation of their sexual behaviour and exploits, thus leading to bias.

\section{Recommendations}

Based on the findings from the study, the following recommendations are made with the hope that they will go a long way in improving the sexual and reproductive health of young people.

\subsection{To the State Government}

The State government should formulate and enforce laws that prohibit coerced or forced sex, rape and other forms of violence to young people and punish perpetrators. Victims and their families must feel safe and supported when approaching the authorities and seeking justice.

\subsection{To Religious Bodies and Non Governental Agencies}

They should continue to preach against forced sex and encourage young people to avoid perpetrating forced sex.

\subsection{To Young People}

Avoid as much as possible sexual risky behaviours that can encourage forced sex.

\section{References}

[1] WHO (2006) Investing in Our Future: A Framework for Accelerating Action for the Sexual and Reproductive Health of the Young People. Manila, Philippines, 12-23.

[2] Cottingham, J. (2005) Policy Brief Promoting and Safeguarding the Sexual and Reproductive Health of Adolescents. WHO, Geneva, 1-3. www.who.int/reproductive-health

[3] UNFPA (2010) UNFPA Framework for Action on Adolescents and Youths. UNFPA, New York, 12-23. www.unfpa.org

[4] Stockman, J.K., Lucea, M.B. and Campbell, J.C. (2013) Forced Sexual Initiation, Sexual Intimate Partner Violence and HIV Risk in Women: A Global Review of the Literature. AIDS and Behavior, 17, 832-847.

https://doi.org/10.1007/s10461-012-0361-4 
[5] Malueke, T. (2010) Sexual Risk Behaviour amongst Young People in the Vhembe District of Limpopo Province. Journal of Interdisciplinary Health Sciences, 15, 1-7.

[6] Krug, E.G., et al. (2000) World Report on Violence and Health. Geneva.

[7] Dixon-Mueller, R. (2011) The Sexual and Reproductive Health of Younger Adolescents: Research Issues in Developing Countries. WHO, Geneva, 45-57.

[8] FMOH (2010) Exploring the Sexual, Reproductive and Socio-Developmental Needs of Adolescents Living with HIV in Nigeria: Positive Action for Treatment Access. $1-33$.

[9] Report, M.W. (2009) Morbidity and Mortality Weekly Report Sexual and Reproductive Health of Persons Aged 10 - 24 Years-United States, 2002-2007.

[10] Koenig, M.A., Zablotska, I., Lutalo, T., Nalugoda, F., Gray, R. and Koenig, M.A. (2004) Coerced First Intercourse and Reproductive Health among Adolescent Women in Rakai, Uganda. International Family Planning Perspectives, 30, 156-163. https://doi.org/10.1363/3015604

[11] Pathela, A.P. and Julia, A. (2010) Sexual Behaviors and Sexual Violence: Adolescents with Opposite- , Same- , or Both-Sex Partners. Pediatrics, 126, 879-886. https://doi.org/10.1542/peds.2010-0396

[12] Robin, L., Brener, N.D., Donahue, S.F., Hack, T., Hale, K. and Goodenow, C. (2002) Associations between Health Risk Behaviors and Opposite-, Same-, and Both-Sex Sexual Partners in Representative Samples of Vermont and Massachusetts High School Students. Archives of Pediatrics and Adolescent Medicine, 15, 349. https://doi.org/10.1001/archpedi.156.4.349

[13] Saewyc, E., Skay, C., Richens, K., Reis, E., Poon, C. and Murphy, A. (2006) Sexual Orientation, Sexual Abuse, and HIV-Risk Behaviors among Adolescents in the $\mathrm{Pa}$ cific Northwest. American Journal of Public Health, 96, 1104-1110. https://doi.org/10.2105/AJPH.2005.065870

[14] Saewyc, B.E.M., Bearinger, L.H., Blum, R.W. and Resnick, M.D. (1999) Sexual Intercourse, Abuse and Pregnancy among Adolescent Women: Does Sexual Orientation Make a Difference ? Family Planning Perspectives, 31, 127-131. https://doi.org/10.2307/2991695

[15] FMOH (2008) National HIV/AIDS and Reproductive Health Survey (NARHS Plus, 2007). 35-67.

[16] Morhason-Bello, I.O., Oladokun, A., Enakpene, C.A., et al. (2008) Sexual Behaviour of In-School Adolescents in Ibadan, South-West Nigeria. African Journal of Reproductive Health, 12, 89-97. http://www.ncbi.nlm.nih.gov/pubmed/20695044

[17] Ndifon, W.O., Ogaji, D.S.T. and Etuk, S.J. (2001) Sexuality, Contraception and Unintended Pregnancy among Female Student Nurses in Calabar, Nigeria. Benin Journal of Postgraduate Medicine, 8, 12-23.

[18] Okonkwo, P.I., Fatusi, A.O. and Ilika, A.L. (2005) Perception of Peers' Behaviour Regarding Sexual Health Decision Making among Female Undergraduates in Anambra State, Nigeria. African Health Sciences, 5, 107-113.

[19] Okereke, C.I. (2010) Unmet Reproductive Health Needs and Health-Seeking Behaviour of Adolescents in Owerri, Nigeria. African Journal of Reproductive Health, 14, 43-54.

[20] Edo State Government (2012) Edo State Strategic Health Development Plan 2010-2015. Benin City, 28.

[21] NPoC and ICF Macro (2008) Nigeria Demographic and Health Survey 2008. Abuja, Nigeria, 13. 
[22] UNFPA (2010) Nigerian Adolescents Population: Selected Socio-Demographic variables. 3-24.

[23] Encyclopedia, T.C. (2005) The Columbia Encyclopedia. 6th Edition, Benin-City, Nigeria, 345.

[24] Song, Y. and Ji, C. (2010) Sexual Intercourse and High-Risk Sexual Behaviours among a National Sample of Urban Adolescents in China. Journal of Public Health, 32, 312-321. http://jpubhealth.oxfordjournals.org/

[25] Lawoyin, O.O. and Kanthula, R.M. (2010) Factors That Influence Attitudes and Sexual Behavior among Constituency Youth Workers in Oshana Region, Namibia. African Journal of Reproductive Health, 14, 55-69.

[26] Abraham, R.J.N. (2002) The Epidemiology of Rape and Sexual Coercion in South Africa. An Overview Social Science \& Medicine, 55, 1231-1244.

https://doi.org/10.1016/S0277-9536(01)00242-8 